\title{
Location and characteristics of the
} reconnection $X$ line deduced from lowaltitude satellite and ground-based observations: 2. Defense Meteorological Satellite Program and European Incoherent Scatter data

\author{
Article
}

Published Version

Lockwood, M., Davis, C. J., Smith, M. F., Onsager, T. G. and Denig, W. F. (1995) Location and characteristics of the reconnection $X$ line deduced from low-altitude satellite and ground-based observations: 2. Defense Meteorological Satellite Program and European Incoherent Scatter data. Journal of Geophysical Research, 100 (A11). p. 21803. ISSN 0148-0227 doi: https://doi.org/10.1029/95JA01339 Available at https://centaur.reading.ac.uk/38797/

It is advisable to refer to the publisher's version if you intend to cite from the work. See Guidance on citing.

Published version at: http://dx.doi.org/10.1029/95JA01339

To link to this article DOI: http://dx.doi.org/10.1029/95JA01339

Publisher: American Geophysical Union 
including copyright law. Copyright and IPR is retained by the creators or other copyright holders. Terms and conditions for use of this material are defined in the End User Agreement.

\section{www.reading.ac.uk/centaur}

\section{CentAUR}

Central Archive at the University of Reading

Reading's research outputs online 


\title{
Location and characteristics of the reconnection $X$ line deduced from low-altitude satellite and ground-based observations 2. Defense Meteorological Satellite Program and European Incoherent Scatter data
}

\author{
M. Lockwood, ${ }^{1}$ C. J. Davis, ${ }^{1}$ M. F. Smith, ${ }^{2}$ T. G. Onsager,${ }^{3}$ and W. F. Denig ${ }^{4}$
}

\begin{abstract}
We present an analysis of a cusp ion step, observed by the Defense Meteorological Satellite Program (DMSP) F10 spacecraft, between two poleward moving events of enhanced ionospheric electron temperature, observed by the European Incoherent Scatter (EISCAT) radar. From the ions detected by the satellite, the variation of the reconnection rate is computed for assumed distances along the open-closed field line separatrix from the satellite to the $\mathrm{X}$ line, $d_{n}$. Comparison with the onset times of the associated ionospheric events allows this distance to be estimated, but with an uncertainty due to the determination of the low-energy cutoff of the ion velocity distribution function, $f(v)$. Nevertheless, the reconnection site is shown to be on the dayside magnetopause, consistent with the reconnection model of the cusp during southward interplanetary magnetic field (IMF). Analysis of the time series of distribution function at constant energies, $f\left(t_{s}\right)$, shows that the best estimate of the distance $d_{o}$ is 14.5 $\pm 2 R_{E}$. This is consistent with various magnetopause observations of the signatures of reconnection for southward IMF. The ion precipitation is used to reconstruct the fieldparallel part of the Cowley D ion distribution function injected into the open low-latitude boundary layer in the vicinity of the $\mathrm{X}$ line. From this reconstruction, the field-aligned component of the magnetosheath flow is found to be only $-55 \pm 65 \mathrm{~km} \mathrm{~s}^{-1}$ near the $\mathrm{X}$ line, which means either that the reconnection $X$ line is near the stagnation region at the nose of the magnetosphere, or that it is closely aligned with the magnetosheath flow streamline which is orthogonal to the magnetosheath field, or both. In addition, the sheath Alfvén speed at the $X$ line is found to be $220 \pm 45 \mathrm{~km} \mathrm{~s}^{-1}$, and the speed with which newly opened field lines are ejected from the $X$ line is $165 \pm 30 \mathrm{~km} \mathrm{~s}^{-1}$. We show that the inferred magnetic field, plasma density, and temperature of the sheath near the $\mathrm{X}$ line are consistent with a near-subsolar reconnection site and confirm that the magnetosheath field makes a large angle $\left(>58^{\circ}\right)$ with the $X$ line.
\end{abstract}

\section{Introduction}

\subsection{Cusp Ion Steps}

Cusp ion steps were first predicted by Cowley et al. [1991] and Smith et al. [1992], based on the "pulsating cusp" model of the effects of pulsed magnetopause reconnection [Lockwood and Smith, 1989, 1990]. Independent of this theoretical work, Newell and Meng [1991] published observed examples of such steps. Lockwood and Smith [1992] applied the theory to the examples presented by Newell and Meng to evaluate the reconnection rate variation.

TRutherford Appleton Laboratory, Chilton, Didcot, Oxfordshire, United Kingdom.

${ }^{2}$ Laboratory for Extraterrestrial Physics, NASA Goddard Space Flight Center, Greenbelt, Maryland.

${ }^{3}$ Institute for the Study of the Earth, Oceans, and Space and Department of Physics, University of New Hampshire, Durham.

${ }^{4}$ Phillips Laboratory, Hanscom Air Force Base, Bedford, Massachusetts.

Copyright 1995 by the American Geophysical Union.

Paper number 95JA01339.

0148-0227/95/95JA-01339\$05.00
Further examples of these signatures were presented by Escoubet et al. [1992] and Lockwood et al. [1993a] and were also interpreted in terms of the pulsating cusp model.

As discussed by Lockwood and Smith [1994], cusp ion steps can also be produced in steady state by spatial variations, and examples of such have recently been studied by Onsager et al. [1995] and Weiss et al. [1995]. Lockwood [1995] has discussed how spatial and temporal reconnection rate variations can be distinguished and has shown that the examples discussed by Lockwood and Smith [1989] and Lockwood et al. [1993a] were temporal, and not spatial, in origin.

The examples presented by Lockwood et al. [1993a] are particularly important because they show the cusp ion steps to lie on the edges of one of a sequence of poleward moving events, observed simultaneously and in very close conjunction by the European Incoherent Scatter (EISCAT) radars. This is in exact accordance with the pulsating cusp theory. Lockwood et al. [1993a] also noted that these combined observations were consistent with the precipitation within each event evolving from cleft (meaning here the open lowlatitude boundary layer, or LLBL) to cusp to mantle as the patch of newly open flux produced by the reconnection burst 
is appended to the tail lobe, as also predicted by the theory (see reviews by Lockwood [1994, 1995]).

In this paper, we consider in detail the cusp ion step observed by Lockwood et al. [1993a] on the equatorward edge of a poleward moving event, seen simultaneously by the EISCAT radars and forming the boundary between cusp and cleft precipitation regions. Lockwood et al. [1993a] used a rough estimate of the magnitude of this step and the repeat period of the events in the EISCAT data to provide an estimate of the location of the reconnection $\mathrm{X}$ line. This estimate is refined here, and an analysis is made of the uncertainties. Newell and Meng [1995] have also repeated the calculation of Lockwood et al. [1993a], but using a different estimate of the size of the step. The analysis presented here is considerably different from both previous studies in both method and results. The analysis is based on the theoretical considerations presented in the companion paper [Lockwood, 1995, this issue] (hereafter referred to as paper 1).

\subsection{Theoretical Implications for Observations by an Equatorward Moving Satellite}

A number of important points can be derived from the theory presented in paper 1 , which are relevant to the analysis of the Defense Meterological Satellite Program (DMSP) F10 spacecraft pass presented in the next section. It is important to note that in this pass the satellite moved equatorward, as in Figures 2 and 12 of paper 1. As a result, the time clapsed since reconncction $\left(t_{s}-t_{o}\right)$ decreases with observing time $t_{s}$ as the satellite approaches the open-closed boundary (OCB).

There will be a low-energy cutoff, $E_{i c}$, for ions. For $E_{i c}>$ $\left(m V_{f X}{ }^{2} / 2\right)$, all ions at this cutoff originated from the $\mathrm{X}$ line (a field-aligned distance $d_{o}$ from the altitude of the satellite), where $V_{f X}$ is the field line velocity along the magnetopause in the vicinty of the $\mathrm{X}$ line and $m$ is the ion mass. For $E_{i c}<$ $\left(m V_{f X}{ }^{2} / 2\right)$, ions will have come from near the magnetic cusp [Lockwood and Davis, 1995a]. Between the points A and B in Figure 2 of paper 1 there is an interesting feature, which reflects the increase in the minimum injected energy (as the field line accelerates away from the $\mathrm{X}$ line) and its subsequent decay (as the rotational discontinuity at the magnetopause straightens out). In this paper we present observations from which we approximately identify the point A, giving the de Hoffmann-Teller velocity at the $X$ line $V_{f X}$, using the procedure which is a refinement of that used by Lockwood et al. [1994]. To do this, we note that the equatorward moving satellite would, at an energy just greater than $\left(m V_{f X}{ }^{2} / 2\right)$, cut the $E_{i c}$ contour three times, whereas for $E_{c} \gg\left(m V_{f X}{ }^{2} / 2\right)$ or $E_{d}$ $<\left(m V_{f X}{ }^{2} / 2\right)$ it would cut it just once at $t_{s}=t_{c}>t_{A}$ and $t_{s}=t_{d}$ $<t_{B}$, respectively. At the energies close to, but greater than, $\left(m V_{f x}{ }^{2} / 2\right)$ the equatorward moving satellite would observe a secondary peak during the decay of $f\left(t_{s}\right)$, as shown by the simulated data in Figure 12 of paper 1.

The velocity filter effect means that the spectrum at any one $t_{s}$ is an ensemble of particles, with the more energetic ions coming from injection points further removed from the reconnection site, compared with the lower-energy ions seen at the same time. As demonstrated by Figures 4, 9, 10, and 11 of paper 1 , the energy of the peak of the spectrum $\left(E_{p}\right)$ bears no fixed relationship with the low-energy cutoff $\left(E_{i c}\right)$ : Although the two are the same at high energies, $E_{i c}$ will fall well below the $E_{p}$ at lower energies.

\section{Combined Satellite and Ground-Based Observations on March 28, 1992}

On March 28, 1992, the DMSP-F10 satellite intersected the cusp region when it was in very close conjunction with the EISCAT radars, operating in the SP-UK-CONV mode. Lockwood et al. [1993a] have described this conjunction, and the reader is referred to their paper for fuller details. In the SP-UK-CONV mode, the EISCAT UHF radar is pointed along the magnetic meridian and takes measurements which integrate the received echoes over 10-s intervals. The VHF radar is operated pointed along the geographic meridian, $15^{\circ}$ to the east of the UHF beam, and simultaneously makes measurements over the same 10-s integration periods. Both radars employ their minimum elevation angles, namely, $20^{\circ}$ for the UHF and $30^{\circ}$ for the VHF. The UHF receiver is gated such that echoes are received from range gates $37.5 \mathrm{~km}$ long, whereas the VHF gates are $75 \mathrm{~km}$ long. The DMSPF10 satellite crossed the UHF radar beam, moving equatorward and to the west at an altitude near $800 \mathrm{~km}$. At the poleward edge of the cusp, the DMSP-F10 satellite was at an MLT just $\triangle M L T=+9$ min greater than that of the EISCAT UHF radar range gate at the same invariant latitude. The corresponding value at the equatorward edge of the cusp was $\Delta M L T=-6 \mathrm{~min}$, and at the equatorward edge of the cleft (open LLBL), $\triangle M L T$ was $-9 \mathrm{~min}$. Hence this conjunction is very close indeed.

Both the EISCAT UHF and VHF radars on this day saw a sequence of poleward moving electron temperature enhancements. A continuous sequence of 11 such events were seen in a 90 -min period. This yields a mean repeat period of nearly $8 \mathrm{~min}$, which is interestingly close to the mean period of other transient events in the cusp and at the dayside magnetopause, namely, poleward moving auroral forms [Fasel, 1995] and flux transfer event signatures [Rijnbeek et al., 1984; Lockwood and Wild, 1993], respectively. These electron density enhancements were not accompanied by any depletions in the plasma density and hence revealed an additional heat source for the ionosphere. Between the boundaries of the cusp region, defined from the DMSP-F10 data by using the criteria used by Newell et al. [1991], EISCAT observed a region of high electron temperature, consistent with previous observations of elevated electron temperatures in the cusp region [Titheridge, 1976; Brace et al., 1982; Curtis et al., 1982; Wickwar et al., 1974; Wickwar and Kofman, 1984; Watermann et al., 1992, 1994; Nilsson et al., 1994]. However, being from ground-based remote sensing observations of much higher time resolution $(10 \mathrm{~s}$ with no antenna scanning), the observations presented by Lockwood et al. [1993a] were the first to show that the electron temperature enhancement was not steady, but was just one of the continuous series of poleward moving events.

Figure 1 shows the three events observed by the EISCAT UHF radar around the time of the satellite pass. The line shows the path of the DMSP-F10 satellite on this invariant latitude-UT plot. The arrows point to the locations where DMSP-F10 observed cusp ion steps bounding the region defined as cusp. This figure shows the electron temperature $T_{e}$ in gray scale, as a function of invariant latitude and UT. The vectors show the plasma flow derived by combining the line-of-sight velocities from the UHF and VHF radars. For the SP-UK-CONV experiment, the UHF radar points along the magnetic meridian and hence, to within a small uncer- 
Experiment : SP-UK-CONV UHF Azimuth 344.8 Degrees

Time Interval : 10:08:00 28 March 1992 - 10:15:00 28 March 1992

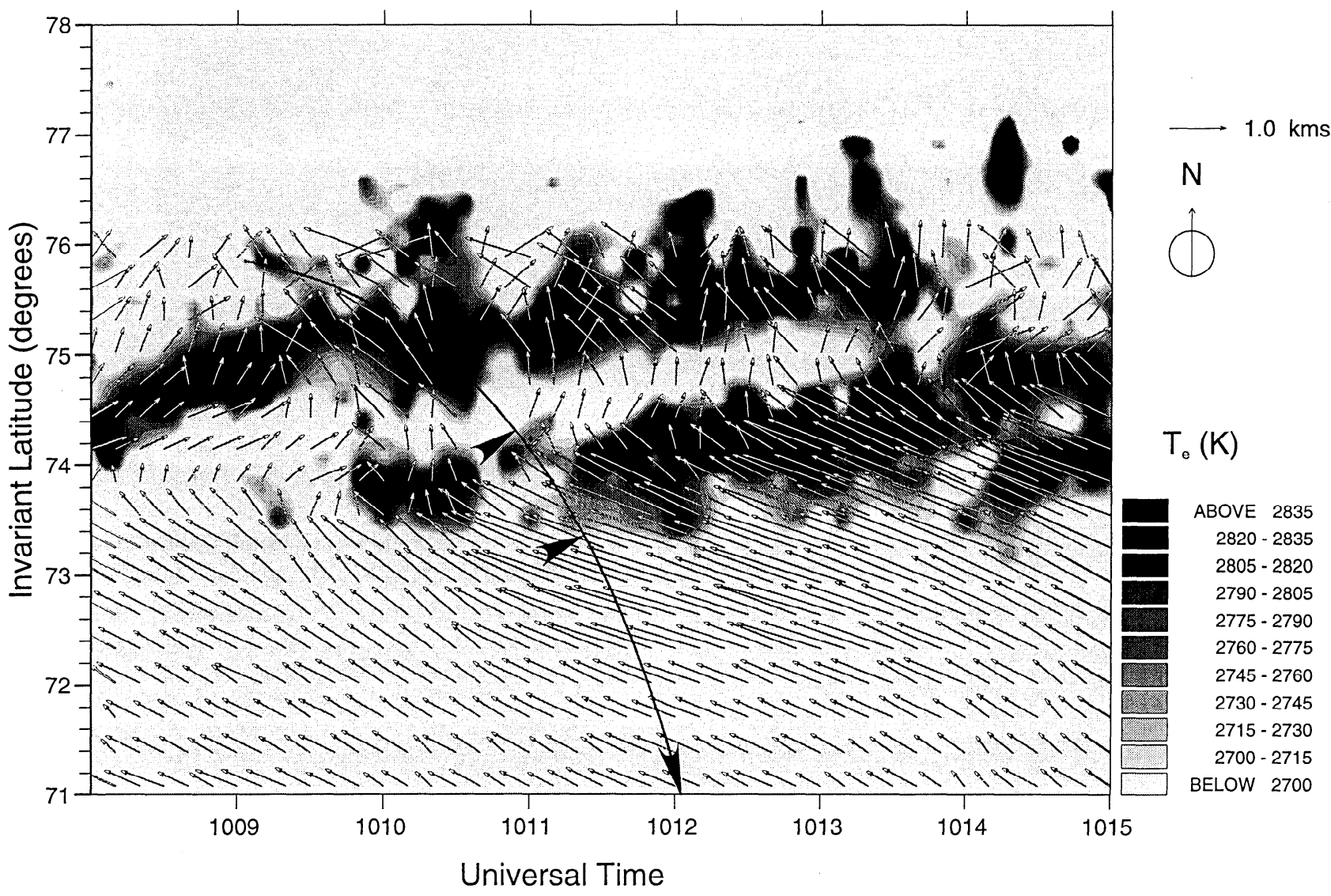

Figure 1. Detail of the poleward moving events seen by the EISCAT UHF radar on March 28, 1992, using the SP-UK-CONV experiment, as reported by Lockwood et al. [1993a]. The line is the locus of the DMSPF10 satellite. The gray scale gives the temperature of the ionospheric electron gas, and the arrows mark the location where DMSP-F10 observed upward steps in the ion dispersion signature on the edges of the "cusp" precipitation. The flow vectors are derived by combining the line-of-sight velocities seen simultaneously by the VHF and UHF radars.

tainty due to field-aligned flow, measures the northward convection component directly. The east-west component is less certain because it is derived by comparing the line-ofsight velocities from the two radars and assuming that the flow is constant along $L$ shells over the spatial separation of the two beams. However, this component is not employed in the present paper. The northward component of the flow, $V_{N}$, was roughly $500 \mathrm{~m} \mathrm{~s}^{-1}$ at all times and locations observed. There are weak enhancements (of about $100 \mathrm{~m} \mathrm{~s}^{-1}$ ) at all latitudes at the onset of each $T_{e}$ event and a weak enhancement (also of about $100 \mathrm{~ms}^{-1}$ ) which propagates poleward with each event around its equatorward edge.

The electron temperature event seen by EISCAT which was coincident in time and space with the cusp precipitation (as seen by DMSP-F10) had an onset at around 1010 UT. Poleward of this was another event, which commenced at 1007 UT and within which the satellite saw precipitation defined to be mantle. The cleft precipitation region observed by the satellite evolved into a third event which was first observed just before 1014 UT. Lockwood et al. [1993a] point out that the EISCAT data reveal the cleft, cusp and mantle regions, defined from the precipitation characteristics observed by the satellite, to be the same type of poleward moving event, but seen at different phases of their evolution. Lockwood and Smith [1993] noted that this is also consistent with the velocity filter effect discussed in paper 1 .

Figure 3 of Lockwood et al. [1993a] provides an overview of the electron and ion data from the DMSP-F10 satellite during this pass. The ion data have 1 -s resolution for each energy channel. The ion instrument has two channels near $955 \mathrm{eV}$ (with different geometric factors), the $f$ values from which are averaged together here. However, because the two overlapping channels are sampled at the beginning and end of each 1-s instrument cycle, they have also been compared to search for aliasing caused by rapid changes within the 1-s period. The calculations of distribution function $f\left(E, t_{s}\right)$ and differential energy flux $J_{E}\left(E, t_{s}\right)$ from the instrument count rates assume that there is an isotropic downward flux of protons. From 1010:58 until 1011:15 the satellite is in the region classified as cusp. As the satellite moves equatorward from this point, the energies of peak $J_{E}$ and $f$ increase until 1011:22, when the values of $J_{E}$ and $f$ fall to the background fluctuation level and there is no evidence of any magnetosheathlike ion precipitation. Between about 1011:13 and 1011:19 there are clear indications of a low-energy cutoff, $E_{i c}$, of the spectrum, but this does not rise in a uniform 
manner. The nature of this rise is one of the main considerations of this paper.

It is by no means obvious how best to determine the value of $E_{i c}$ at each observation time $t_{s}$. One problem is that any inelastic ion scattering would make this time-of-flight cutoff difficult to define. Even more important, aliasing will smear this cutoff if there are significant changes in the spectrum within the 1-s cycle time of the instrument, and the limited energy resolution of the detector also makes it difficult to estimate the cutoff. In their paper, which employed $E_{i c}\left(t_{s}\right)$ to compute the variation of the magnetopause reconnection rate, Lockwood and Smith [1992] used the energy where the differential energy flux fell to a tenth of its peak value, and a similar approach (but different definition) has been adopted by Newell and Meng [1995]. Lockwood and Smith [1992] did note that such definitions were arbitrary, but found that other definitions did not alter their main result, namely, that nearly all the reconnection came in three short pulses for the pass that they studied. However, in the present paper we wish to make further deductions from $E_{i c}\left(t_{s}\right)$, and the effect of employing any arbitrary definitions has to be studied in detail. We wish to make two points about the definitions adopted by both Lockwood and Smith [1992] and Newell and Meng [1995]. First, $E_{i c}$ will be employed with time-of-flight considerations, and we believe that it is better to use the velocity space density (distribution function), $f\left(E, t_{s}\right)$, to define $E_{i c}$ and not the differential energy flux, $J_{E}\left(E, t_{s}\right)$. The latter is proportional to $\left(f . E^{2}\right)$ and hence accentuates features at high energies and suppresses those at lower energies, making the cutoff much harder to define at lower energies. Second, it is not correct to fit the spectrum at any one $t_{s}$ to define $E_{i c}$. This is because, as discussed in section 2 of paper 1 , the velocity filter effect results in the spectrum at any one $t_{s}$ being made up of ions from a variety of points on the magnetopause and hence is distorted by spatial variations in the magnetosheath ion temperature and density along the magnetopause and by the variation of the ion acceleration factor on crossing the magnetopause as the field lines accelerate and straighten. As a result, the peak $f$ (or $J_{E}$ ) has no bearing on the value of $E_{i c}$. We here inspect not only plots of $f(E)$ for every observation time $t_{s}$, but also plots of $f\left(t_{s}\right)$ for every energy channel of the instrument (i.e., at constant $E$ ) in order to determine $E_{i c}$.

As there is, at this stage, no obvious way to estimate the low-energy cutoff, $E_{i c}$, we here adopt a number of different definitions, shown in Figure 2 as a function of observation time $t_{s}$. In the remainder of this section and in later sections we discuss these estimates of $E_{i c}$ and the reliability of each of them.

Figures $3 \mathrm{a}, 3 \mathrm{~b}$, and $3 \mathrm{c}$ give successive $f(E)$ on logarithmic scales for four 1-s integrations, $1 \mathrm{~s}$ apart. The last spectrum in each panel (solid line) is repeated as a dotted line in the subsequent one to allow comparison. For each panel the onecount level is plotted as the lower solid line, with a step near $1 \mathrm{keV}$ due to the discontinuous change in the instrument geometric factor. Note that each spectrum is labeled by the time at the end of the $1-\mathrm{s}$ instrument cycle during which it was recorded. Comparison with Figures 4, 10, and 11 of paper 1 shows that the evolution of the spectrum observed here is broadly as predicted by the reconnection model (remembering for this equatorward moving satellite that $\left(t_{s}-t_{o}\right)$ decreases with $t_{s}$ ).

The low-energy cutoff $E_{i c}$ is clearest at the equatorward edge of the cusp, and hence it is easiest to follow its vari-

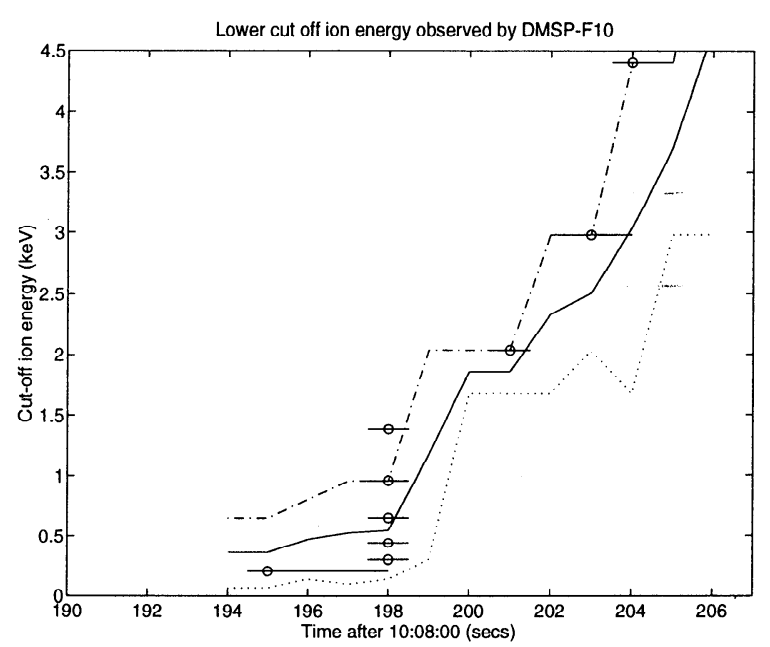

Figure 2. Various estimates of the lower cutoff ion energy, $E_{i c}$, as a function of observation time, $t_{s}$, measured here after 1008 UT. The dotted line shows $E_{l}$, the energy where $f(E)$ falls to the one-count level; the dot-dashed line shows $E_{p}$, the energy of the peak distribution function $f\left(E_{p}\right)$; the solid line is $\left[E_{i c}\right]_{E}$, the mean of $E_{l}$ and $E_{p}$; and the horizontal bars are deduced from $f\left(t_{s}\right)$, the midpoints of which (open circles) are termed $\left[E_{i c}\right]_{\text {. }}$.

ation by considering the last spectrum shown (for 1011:23 in Figure $3 c$ ) first. At this time, $f(E)$ shows a clear peak at 2.98 $\mathrm{keV}$ but drops to the one-count level in the energy bin below this peak. Hence between these two bins there is a sharp fall in $f(E)$ with decreasing $E$; in other words, the low-energy cutoff $E_{i c}$ lies between the two. We here use the nomenclature that $E_{1}$ is the center of the energy bin in which $f(E)$ falls to or below the one-count level and that $E_{p}$ is the center of the energy bin detecting peak $f$. One possible estimate of $E_{i c}$ from the $f(E)$ spectra, which we term $\left[E_{i c}\right]_{E}$, is $\left(E_{l}+E_{p}\right) / 2 \pm$ $\left(E_{p}-E_{l}\right) / 2$. We stress that $E_{l}$ and $E_{p}$ are extreme limits for $E_{i c}$ and the true value will lie between the two. For all distribution functions in Figure $3 \mathrm{c}, E_{I}$ and $E_{p}$ are just one energy bin apart, and both rise with $t_{s}$. This rise is also seen in Figure $3 \mathrm{~b}$ but is much more rapid, with $E_{l}$ rising with $t_{s}$ from $96 \mathrm{eV}$ at $1011: 17$ to $1.38 \mathrm{keV}$ at $1011: 20$, while in the same period $E_{p}$ rises from $950 \mathrm{eV}$ to $2.03 \mathrm{keV}$. Because of this rapid change, the form of the distribution function at 1011:19 is distorted by the effect of aliasing as $E_{i c}$ rises rapidly. In other words, at the end of this 1-s integration period, the detector is no longer seeing lower-energy ions which were present at its start. This is confirmed by comparison of the two overlapping 955-eV channels at this time, the lowest-energy channel of the upper half of the instrument recording no ions at the end of the cycle, while fluxes were not reduced at this energy in the highest channel of the lower half, which was sampled at the start of the cycle.

Both $E_{l}$ and $E_{p}$ can be found by using an automated algorithm. Only one subjective decision was required, because at 1011:18 $f(E)$ never falls to the one-count level. However, this is due to one or two background counts at the lowest energies, which may well have resulted from scattering. Similar low-level counts were seen below the defined $E_{l}$ in the subsequent two spectra. At 1011:18, a clear decay to this background level can be defined, and from this $E_{l}$ was taken to be $140 \mathrm{eV}$. Figure $3 \mathrm{a}$ shows that the spectrum changes relatively slowly poleward of the rapid rise shown in Figure $3 b$. 
a.

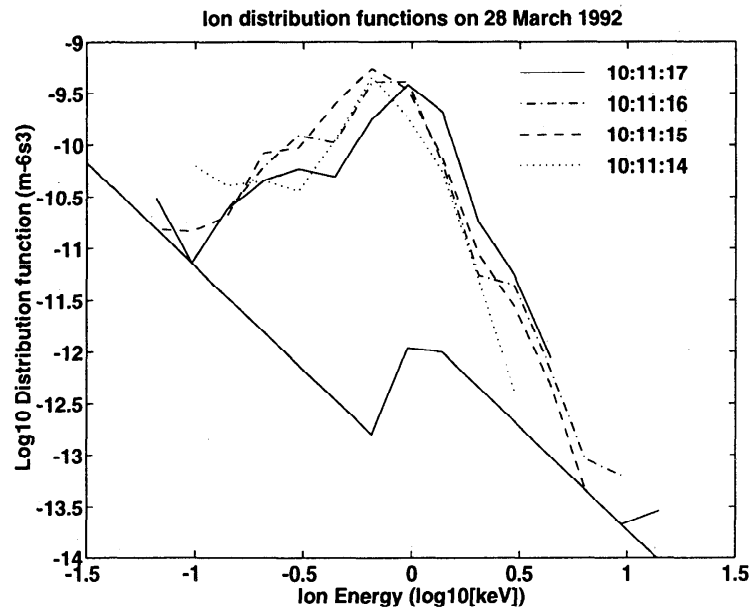

b.

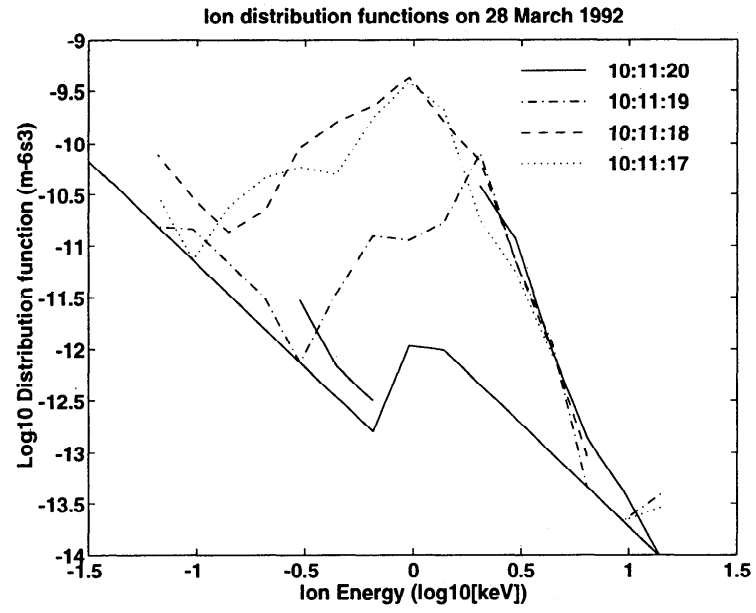

c.

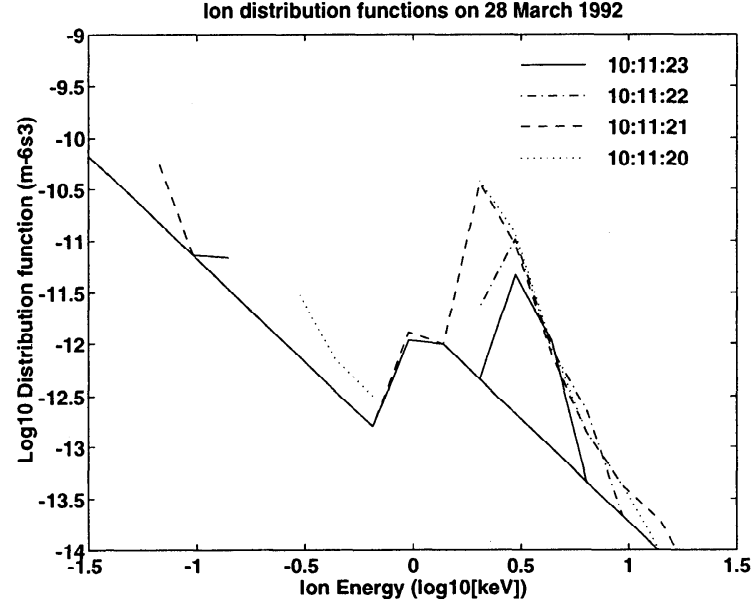

Figure 3. Sequential ion distribution functions, $f(E)$, observed by DMSP-F10 on March 28, 1992, shown on a log-log scale. The lower solid line is the one-count level of the detector. (a) 1011:14 - 1011:17 UT; (b) 1011:17-1011:20 UT; and (c) 1011:20-1011:23 UT. The time label refers to the time at the end of the 1-s instrument cycle in which each was recorded.

Figure 2 shows $E_{l}$ (dotted line), $E_{p}$ (dot-dashed line) and $\left[E_{i c}\right]_{E}$ (solid line) as a function of observation time, $t_{s}$, which is here defined to be zero at 1008:00. All three reveal the cusp ion step at times near $t_{s}=199 \mathrm{~s}$, as identified from the spectrogram by Lockwood et al. [1993a]. At the higher energies (after 1011:20) there is little doubt about the validity of this estimate for $E_{i c}$ because $E_{p}$ and $E_{l}$ are just one energy bin apart, as in the dashed line in Figure 4 of paper 1. However, before this time there is a much larger uncertainty because $E_{p}$ and $E_{l}$ are several energy bins apart (as in the dotted line in Figure 4 of paper 1), and from this we would expect $\left[E_{i c}\right]_{E}$ to be an overestimate of the real $E_{i c}$ at these times.

In this paper, we obtain further information about $E_{i c}$ by studying the variation of $f$ with observation time, $t_{s}$, for each energy bin. The results are shown in Figure 4. As in Figure 3 , the solid trace in one panel also appears as a dotted trace in the next to allow comparisons. The distribution function, $f$, is usually given as a function of ion velocity $v$ or energy $E$ at a time $t_{s}$ and thus denoted by $f(v)$ and $f(E)$, respectively. In Figure 4 we consider $f$ as a function of $t_{s}$ at constant $v$ (and $E$ ) and hence adopt the notation $f\left(t_{s}\right)$. Without scattering, smoothing or aliasing, the value of $f\left(t_{s}\right)$ for each energy channel would vary as the satellite traversed the mantle/cusp/cleft region but would encounter a sudden drop to the one-count level (when $E_{i c}$ rose above the energy of the channel, $E$ ) as the satellite emerged on the equatorward side of the cusp/cleft region. Figure $4 \mathrm{~d}$ shows that this decay can be clear but not sudden. As a result, the time that $E_{i c}$ equals the energy of that channel can be determined, but with some uncertainty. The decay occurs later at higher energies, as expected. However, Figures $4 \mathrm{~b}$ and $4 \mathrm{c}$ show that the decay is sudden and almost simultaneous at all energy channels between $300 \mathrm{eV}$ and $1.38 \mathrm{keV}$. This is because of the cusp ion step shown in Figure 2. In these cases, the decay to the background fluctuation level of $f$ equatorward of the cusp occurs in just one or two instrument cycles and the uncertainty in the $t_{s}$ when $E=E_{i c}$ is therefore only $\pm 0.5 \mathrm{~s}$ or \pm 1.0 $\mathrm{s}$, respectively. The horizontal bars in Figure 2 show the times of the bulk of this decay at each energy level, as scaled from Figure 4, and the open circles represent the times at the center of each decay. Because they are defined from the time series $f\left(t_{s}\right)$, we refer to these open circles as $\left[E_{i c}\right]_{t}$.

It is useful to compare these times (when $E_{i c}$ crosses the energy $E$ of each instrument channel) and $\left[E_{i c}\right]_{t}$ estimates with the plotted variations of $E_{p}, E_{l}$ and $\left[E_{i c}\right]_{E}$ shown in Figure 2. It is clear that $E_{l}$ does not agree very closely if $E_{i c}$ is taken to be at the end of the decay in $f\left(t_{s}\right)$, whereas $E_{p}$ does agree well if $E_{i c}$ is taken to be at the start of each decay, but only for the higher $E_{t c}$. Figure 2 does confirm that these two are extreme limits for $E_{i c}$. In the next section, we show that the conclusions of Lockwood et al. [1993a] and Newell and Meng [1995] are critically dependent on how $E_{i c}$ is defined.

\section{Variation of the Reconnection Rate}

The equations derived by Lockwood and Smith [1992] can be applied to the variations of the various estimates of the low-energy cutoff, $E_{i c}$, discussed in the previous section. The reconnection rate at the magnetopause $\mathrm{X}$ line, $\epsilon_{y}\left(t_{o}\right)$, is calculated by using equation (7) of paper 1 . As discussed in paper 1, not only does the value of $\epsilon_{y}$ depend on the gradient $d E_{l c} d d t_{s}$, but this term is also multiplied by a factor $E_{c}^{-3 / 2}$. Hence periods of low $\epsilon_{y}$ give steep gradients in the cutoff energy $E_{i c}$ when it is large, but much less obvious gradients when $E_{i c}$ is low. Hence, although inspection of cusp ion steps in any series of estimates of $E_{i c}$ (as used by Lockwood et al. [1993a] and Newell and Meng [1995]) will reveal periods of 
a.

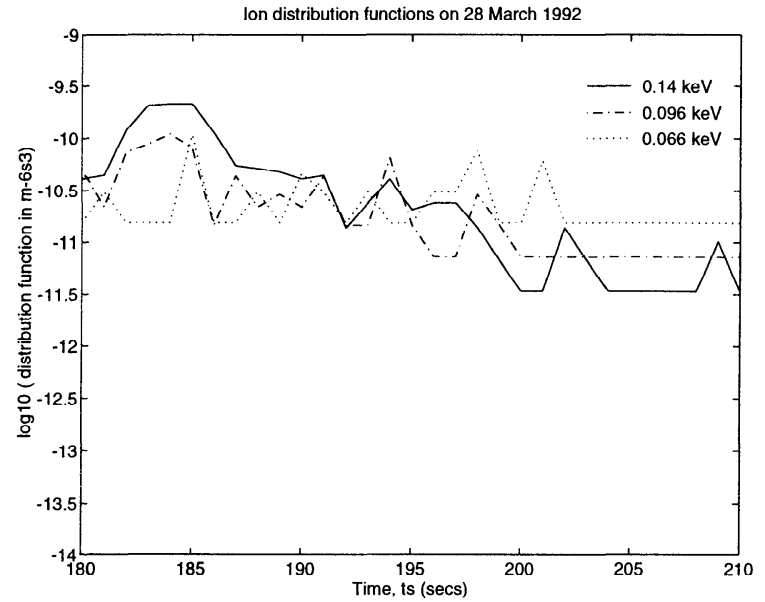

b.

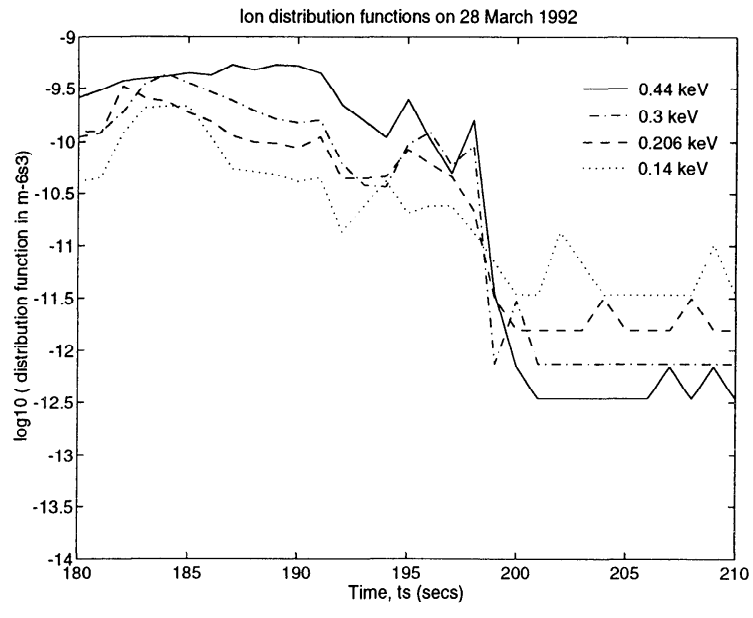

c.

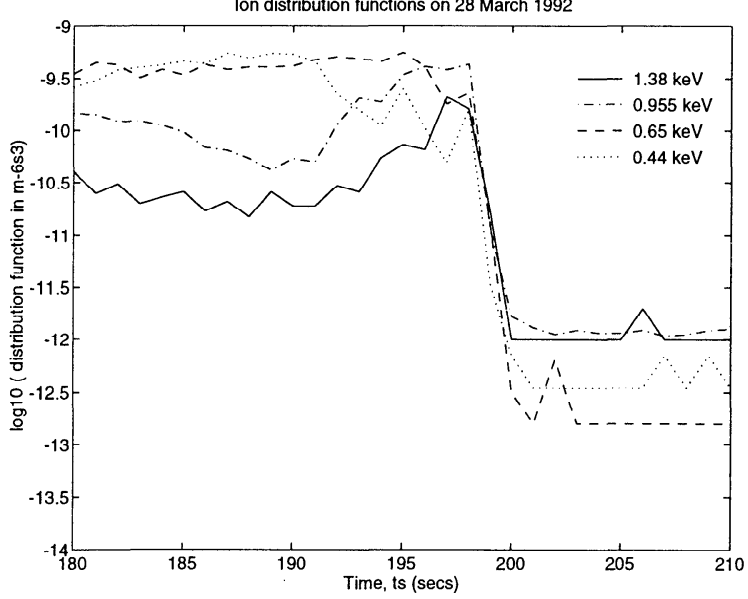

d.

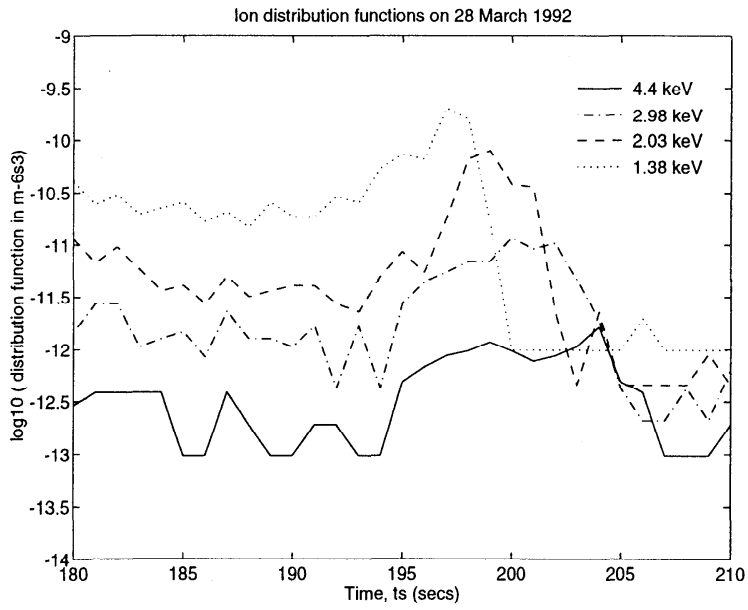

low reconnection rate, the full duration of those low-rate periods is not determined unless equations (7) and (1) of paper 1 are used to compute $\epsilon_{y}\left(t_{o}\right)$.

Figure 5 shows the variation of reconnection rate with time, deduced by using the two estimates $\left[E_{i c}\right]_{E}$ (solid line) and $\left[E_{i c}\right]_{t}$ (dashed line), as described in the previous section and shown in Figure 2. The OCB is assumed to be $L$ shell aligned so that the convection component normal to the $\mathrm{OCB}, V_{c}$, is directly measured by the UHF radar. Both plots assume a field-aligned distance $d_{o}$ from the satellite to the $\mathrm{X}$ line of $16 R_{E}$. The analysis is not extended back to periods before 1011:14 because, as discussed in the next section, we infer this to be the time that $E_{i c}$ is close to the point $\mathrm{A}$ in Figure 2 of paper 1 (before which no ions seen can come from the $\mathrm{X}$ line). However, this is sufficient to show the end of the reconnection pulse which gave rise to the cusp precipitation and the whole of the pulse which gave the cleft precipitation. It can be seen that large and spurious spikes appear in the variation derived by comparing successive spectra because the errors in deriving the cutoff gradient are so large. Figure 5 also demonstrates how a small change in the estimate of $E_{i c}$ makes a large difference to the estimated timing of the first pulse. This is because even very small changes in the energy of low-energy ions produce large changes in their flight time and, by equation (1) of paper 1 , in $t_{0}$. At higher energies, the flight time is not so sensitive to the value of $E_{i c}$, and the timing of the second pulse is more precisely defined.

Lockwood and Smith [1992] point out that the other factor which strongly influences the timing of the pulses is the assumed value for the distance $d_{o}$. This is illustrated here by Figure 6 , which uses the estimates of $\left[E_{i c}\right]_{t}$ with extreme values for $d_{v}$ of 8 and $35 R_{E}$. The timing of both reconnection pulses is altered, but that of the first pulse is most influenced, for the same reasons as described above. The error bars shown in Figure 6 (for the $d_{o}=35 R_{E}$ case only) are due to the uncertainties in determining the $t_{s}$ when $E_{i c}$ becomes equal to the energy of each channel [Lockwood and Davis, 1995b] and are much smaller than those for successive spectra [Lockwood and Smith, 1992] for the reasons discussed in paper 1 .

\section{Distance to the Reconnection $X$ Line}

As discussed in paper 1, the variations of $\epsilon_{y}$ can be compared with the EISCAT observations of the poleward moving events to estimate the distance $d_{o}$ from the $\mathrm{X}$ line to the satellite.

The period of low reconnection found in Figures 5 and 6 arises from the steep rise in the estimates of $E_{i c}$ in Figure 2. This occurs between about 1011:13 and 1011:19 UT (193$199 \mathrm{~s}$ after 1008:00), exactly when the satellite is between the second poleward moving event seen by EISCAT in Figure 1 and the region which later develops into the third event. Hence we can associate the two pulses in the

Figure 4. Time series of distribution function $f\left(t_{s}\right)$, observed at an energy $E$ by DMSP-F10 on March 28, 1992, where $t_{s}$ is measured relative to a reference time of 1008:00, for (a) $E$ of $66 \mathrm{eV}, 96 \mathrm{eV}$, and $140 \mathrm{eV}$; (b) $E$ of $140 \mathrm{eV}, 206 \mathrm{eV}$, $300 \mathrm{eV}$, and $440 \mathrm{eV}$; (c) $E$ of $440 \mathrm{eV}, 650 \mathrm{eV}, 955 \mathrm{eV}$, and $1.38 \mathrm{keV}$; and (d) $E$ of $1.38 \mathrm{keV}, 2.03 \mathrm{keV}, 2.98 \mathrm{keV}$, and $4.4 \mathrm{keV}$. 


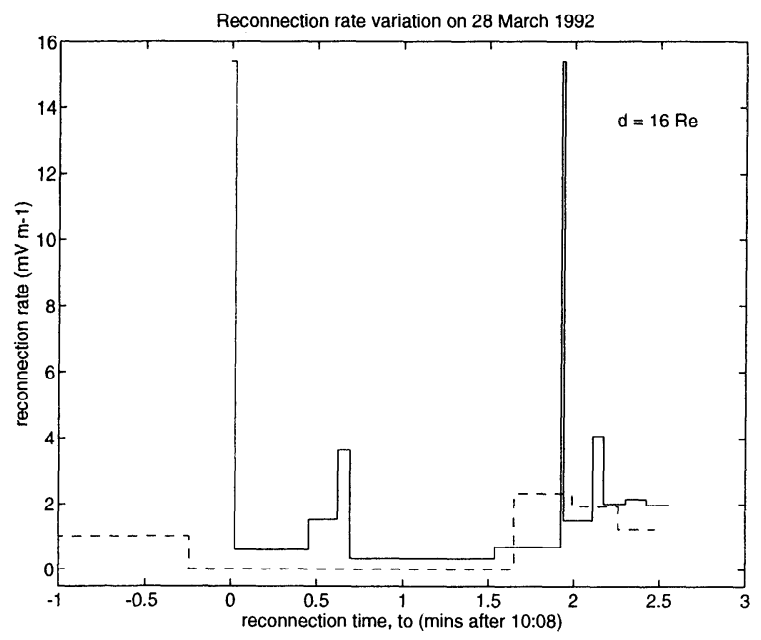

Figure 5. Variation of reconnection rate, $\epsilon_{y}$, for an assumed distance from the satellite to the $\mathrm{X}$ line, $d_{o}$, of $16 R_{E}$ and using $E_{i c}=\left[E_{i c}\right]_{E}$ (solid line) and $E_{i c}=\left[E_{i c}\right]_{t}$ (dashed line).

reconnection rate with the second and third events in Figure 1. This constrains the value of $d_{o}$, because not only must the interval between the two points be matched, but each reconnection pulse must be a certain time ahead of the appearance of the corresponding event of high electron temperature seen by EISCAT. This delay will in part be due to the flight times of the ions (which cause a delay before large fluxes of electrons arrive such that quasi neutrality is not violated), but will also reflect any rise time for the heating of the ionospheric electron gas. There is no reason to expect this delay to be different for the two events.

Figure 7 plots this delay as a function of the assumed dis tance $d_{o}$, using the four estimates of $E_{i c}$ : the extreme values $E_{l}$ (dotted lines) and $E_{p}$ (dot-dashed lines) as well as $\left[E_{i c}\right]_{t}$ (dashed lines) and $\left[E_{i c}\right]_{E}$ (solid lines). In each case, two lines are shown; the steeper one of each pair is for the first reconnection pulse (the timing of which is a more sensitive function of $d_{o}$, as shown by Figures 5 and 6) and the other is for the second pulse. Assuming that this delay is the same for the two events, where a pair of lines cross gives the value of the delay. More important, it also gives the distance $d_{o}$ if we assume that the two pulses are reconnected at the same

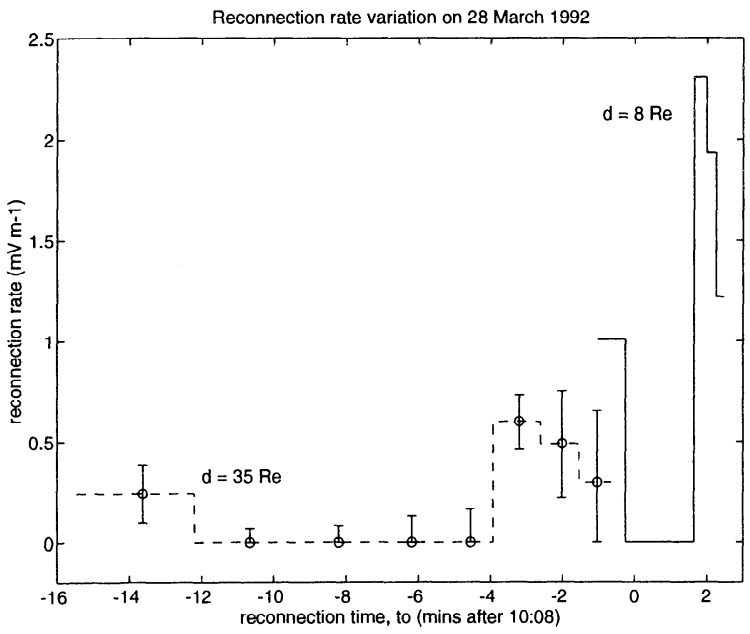

Figure 6. Variation of reconnection rate $\epsilon_{y}$ for $d_{o}=8 R_{E}$ (solid line) and $d_{o}=35 R_{E}$ (dot-dashed line) using $E_{i c}=\left[E_{i c}\right]_{t}$.

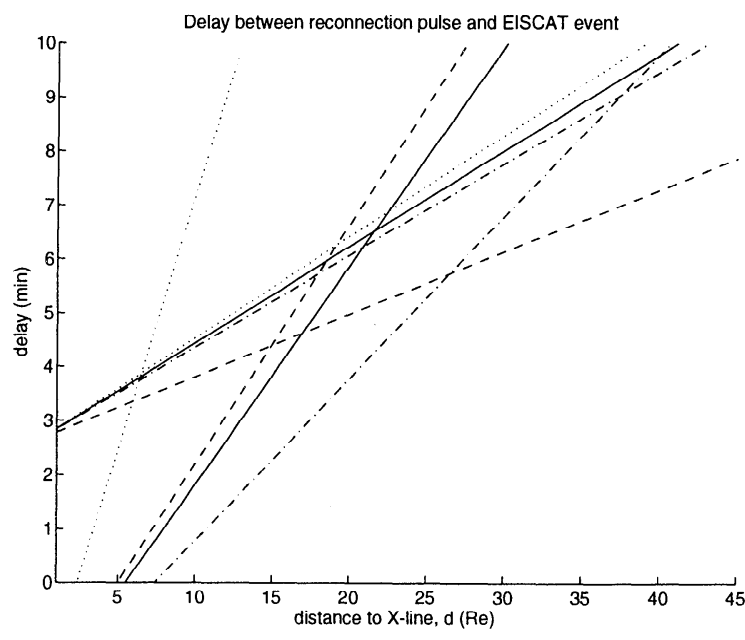

Figure 7. The delay between the reconnection pulse and the onset of the associated event seen by EISCAT, as a function of the assumed distance to the $\mathrm{X}$ line, $d_{o}$. Estimates for $E_{i c}$ used are given in Figure 2: $E_{l}$ (dotted lines), $\left[E_{i c}\right]_{t}$ (dashed lines), $\left[E_{i c}\right]_{E}$ (solid lines), and $E_{p}$ (dot-dashed lines). The lines are in pairs, the steeper of the pair being for the first event/reconnection pulse, the other being for the second. The intersection point of each pair gives the distance $d_{o}$.

site. The delay required between the reconnection pulse and the appearance of the event varies from $3.5 \mathrm{~min}$ for $E_{l}$ to almost $8 \mathrm{~min}$ for $E_{p}$. The values of around $5 \mathrm{~min}$ for the other two estimates are highly plausible considering the timescales for ionospheric heating and the elapsed time since reconnection before significant (cusp) fluxes of ions and electrons arrive in the topside ionosphere [Lockwood and Davis, 1995a].

The use of the one-count level, $E_{l}$, yields a $d_{o}$ of about 6 $R_{E}$, which would only be on the magnetopause (at the local magnetic cusp) for a highly compressed dayside magnetosphere. The $d_{o}$ obtained by using the peak of the distribution function, $E_{p}$, is about $32 R_{E}$, which places the reconnection site somewhere close to the magnetic cusp in the opposite hemisphere for a weakly compressed magnetosphere. Since these two should be regarded as extreme limits of the range of $E_{i c}$, we can conclude that the data are broadly consistent with a reconnection site which was somewhere on the dayside magnetopause.

The estimates $\left[E_{i c}\right]_{E}$ and $\left[E_{i c}\right]_{t}$ yield $d_{o}$ of $22 R_{E}$ and 14.5 $R_{E}$, respectively. If inelastic ion scattering or noise increases counts at energies below $E_{i c}$, the energy at the one-count level, $E_{l}$, is a poor estimate of $E_{i c}$, and hence the resulting estimate of $d_{o}$ of $6 R_{E}$ should be disregarded. However, comparison of the $f(E)$ in Figure 3 provides an indication why $\left[E_{i c}\right]_{t}$ is more reliable than $\left[E_{i c}\right]_{E}$. Figure 4 of paper 1 demonstrates how $E_{p}$ and $E_{i c}$ should be similar at high values (as in the dashed, cleftlike spectrum), but how $E_{p}$ will be considerably greater than $E_{i c}$ when $E_{i c}$ has fallen to low values (as in the dotted cusplike spectrum). Figure 2 demonstrates that $\left(E_{p}-\left[E_{i c}\right]_{E}\right)$ remains almost constant, which is therefore inconsistent with Figure 4 of paper 1, whereas $\left(E_{p}\right.$ $\left.\left[E_{i c}\right]_{t}\right)$ increases with decreasing $E_{p}$, as required by Figure 4 of paper 1. In addition, in the next section, we show that only $\left[E_{i c}\right]_{t}$ makes the $f\left(t_{s}\right)$ variations shown in Figure 4 consistent with the predictions given in Figures 11 and 12 in paper 1. As a result, we conclude that the best estimate of $E_{i c}$ is $\left[E_{i c}\right]_{t}$ and the best estimate of $d_{o}$ is $14.5 R_{E}$. From the 
temporal separation of the $\epsilon\left(t_{o}\right)$ estimates for this $d_{o}$, we estimate that the error in $d_{o}$ is $\pm 2 R_{E}$.

\section{The Cowley D Distribution Function at the Reconnection Site}

As discussed in section (4) of paper 1, ions injected near the reconnection $X$ line will form the low-energy ion cutoff, $E_{i c}\left(t_{s}\right)$, in the ion spectrogram detected by a low-altitude satellite, for all locations equatorward of the point A such that $E_{i c}>E_{A}=m V_{f X}{ }^{2} / 2$. For adiabatic, scatter-free motion, both the energy $E_{i c}$ and, by Liouville's theorem, $f\left(E_{i c}\right)$ will be conserved on traveling from the $\mathrm{X}$ line to the satellite. Hence, by taking the values of $f\left(E_{i c}\right)$ at various observation times, $t_{s}$, we can reconstruct the field-parallel part of the Cowley D distribution injected near the $\mathrm{X}$ line. The values of $f\left(E_{i c}\right)$ are derived from Figure 4, by taking the value of $f\left(t_{s}\right)$ for each energy channel, immediately before the onset of the decay in $f$ as the satellite traveled through the equatorward boundary of the magnetosheathlike precipitation. Inspection of Figure 4 shows that $f\left(t_{s}\right)$ for most $E$ is usually steady prior to the decay, and this is a good estimate of $f\left(E_{i c}\right)$, [Lockwood and Davis, 1995b]. The results are shown by the open circles in Figure 8. Later in the crossing, when $E_{l}$ and $E_{p}$ are just one channel apart, $f\left(E_{p}\right)$ values derived from Figure 3 are also good estimates of $f\left(E_{i c}\right)$ and these are also shown in Figure 8 , as crosses. Figure 8 reveals that this procedure produces a consistent distribution function, which is close in form to a drifting Maxwellian. The data point which is furthest from this form is that at the peak, and is taken near the steepest gradient of the step in the $E_{i c}$ estimates (Figure 2) where both $E_{i c}$ and $f\left(E_{i c}\right)$ change rapidly. This data point is therefore likely to have been influenced by aliasing. Note, however, that in least squares fitting this reconstructed spectrum, all points were given equal weight.

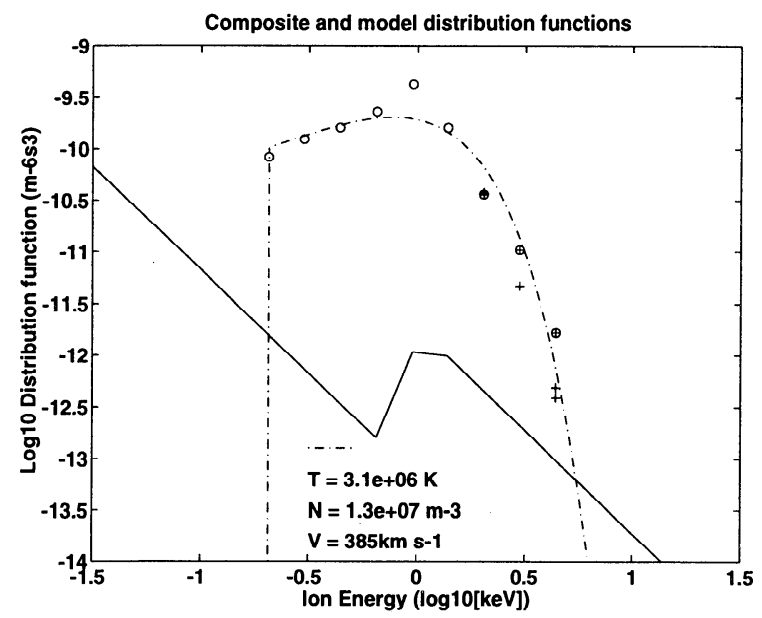

Figure 8. The Cowley D distribution function in the (open) LLBL close to the reconnection $X$ line. The open circles are the values of $f\left(E_{i c}\right)$, taken from the last integration point before the fall in $f\left(t_{s}\right)$ shown in Figure 4 . The crosses are $f\left(E_{p}\right)$ for those distribution functions where $E_{l}$ and $E_{p}$ are only one energy channel apart. The solid line is the onecount level. The dot-dashed line is the least squares fit to these data points for a truncated drifting Maxwellian of fieldparallel temperature $T=3.1 \times 10^{6} \mathrm{~K}$, "one-dimensional" density $N . A=1.3 \times 10^{7} \mathrm{~m}^{-3}$, and field-aligned bulk velocity $V_{p}=385 \mathrm{~km} \mathrm{~s}^{-1}$.
The dot-dashed line in Figure 8 is the best fit drifting Maxwellian distribution to these points. This distribution has a field-aligned bulk flow speed of $V_{p X}=385 \mathrm{~km} \mathrm{~s}^{-1}$, a fieldparallel ion temperature of $T=3.1 \times 10^{6} \mathrm{~K}$, and a density of $N=1.3 A \times 10^{7} \mathrm{~m}^{-3}$, where $A$ is the ion anisotropy [see Hill and Reiff, 1977]. The least squares fitting gives an uncertainty in $V_{p X}$ of $\pm 30 \mathrm{~km} \mathrm{~s}^{-1}$. In Figure 8 , the dot-dashed line has been truncated at a velocity of $165 \mathrm{~km} \mathrm{~s}^{-1}$ for protons. The theory presented in paper 1 shows this velocity is equal to $V_{f x}$, the de Hoffmann-Teller velocity close to the $\mathrm{X}$ line. To understand this estimate of the minimum injected velocity at the $X$ line, we refer to section 5 of paper 1 and the predictions for the behaviour of $f(E)$ and $f\left(t_{s}\right)$ given in Figures 11 and 12 of that paper.

Figure 3 shows that the spectra evolve very rapidly in the period 1011:15-1011:20, $f(E)$ changing in form from that predicted for $\left(t_{s}-t_{o}\right)=520 \mathrm{~s}$ in Figure 11 of paper 1 to that predicted for $\left(t_{s}-t_{o}\right)=250$ s (Figure 10 paper 1 ). This rapid change is associated with the cusp ion step featured in Figure 2 and results in a highly time aliased spectrum at 1011:18. Prior to this change, the small ridge in the cut-off predicted in paper 1 is observed, and is present at 1011:16 and 1011:17 (Figure 3), which should be compared with the predicted spectra for $\left(t_{s}-t_{o}\right)$ of $500 \mathrm{~s}$ and $520 \mathrm{~s}$ in Figure 11 of paper 1. This feature less marked for $1011: 15$ and cannot be resolved from the background count rate at 1011:14. From the model variation predicted in Figure 11 of paper 1, we would therefore define the best estimate of the time $t_{A}$ to be between 1011:14 and 1011:15 $\left(t_{s}=194-195 \mathrm{~s}\right.$ in Figures 2 and 4), and the energy $E_{A}$ to be $140 \pm 50 \mathrm{eV}$. This corresponds to $V_{f X}$ of $165 \pm 30 \mathrm{~km} \mathrm{~s}^{-1}$. We note that the field line acceleration effect on the lower-energy ions, as discussed in paper 1, will tend to make this an overestimate of $V_{f x}$.

Figure 4 shows two features in $f\left(t_{s}\right)$ somewhat like the minimum in $f\left(t_{s}\right)$ predicted for $444 \mathrm{eV}$ prior to the final cutoff in Figure 12 of paper 1. There is a small minimum in $f\left(t_{s}\right)$, shortly before the major decay. The major difference between these data and the theoretical predictions is that most of the decay occurs almost simultaneously at all energy channels in Figure 4, whereas in Figure 12 of paper 1 it occurs later for the higher-energy channels. This is due to the cusp ion step (i.e., the period of negligibly small reconnection rate) for the data, whereas the model simulations in paper 1 were for steady state. A minimum in $f\left(t_{s}\right)$ can be seen between $t_{s}$ of between 192 and $194 \mathrm{~s}$ in Figure 4, at $E$ of $440 \mathrm{eV}, 300 \mathrm{eV}, 206 \mathrm{cV}$, and $140 \mathrm{cV}$. However, there is a second minimum at $t_{s}=197 \mathrm{~s}$ for $440 \mathrm{eV}$ and 300 $\mathrm{eV}$ which could also be interpreted as the predicted minimum. The latter would give $t_{A}=197 \mathrm{~s}(1011: 17)$ and $E_{A}=$ $206 \mathrm{eV}$; a result that is not consistent with the $f(E)$ shown in Figure 3. We attribute this second minimum to the effects of limited time, pitch angle, and energy resolutions, with time aliasing complicated by the variations in reconnection rate, such that $\left(t_{s}-t_{o}\right)$ is a steplike function of $t_{s}$. Note also that temporal fluctuations in sheath density and temperature will appear in $f\left(t_{s}\right)$. The earlier minimum, on the other hand, is present in four (rather than two) energy channels, and two (rather than one) integration periods and is consistent with the values of $t_{A}$ and $E_{A}$ derived from $f(E)$. Figure $4 \mathrm{a}$ shows that this minimum cannot be distinguished from fluctuations in the count level for $E<E_{A}$ of 66 and $96 \mathrm{eV}$; such counts can thus be attributed to ions scattered from higher energies. Hence, from both $f(E)$ and $f\left(t_{s}\right)$, we derive a best estimate of $E_{A}$ of $140 \pm 50 \mathrm{eV}$ and $t_{A}$ of $195.5 \pm 0.5 \mathrm{~s}$. This corresponds 
to an X line outflow speed $V_{f X}$ of $165 \pm 30 \mathrm{~km} \mathrm{~s}^{-1}$. This estimate of $E_{A}$ is significantly less than $\left[E_{i c}\right]_{E}$ at this time but very close to the value of $\left[E_{i c}\right]_{t}$. Hence this further supports the best estimate of $d_{o}=14.5 R_{E}$ derived by using $\left[E_{i c}\right]_{r}$.

We can use the estimates of $V_{p X}=385 \pm 30 \mathrm{~km} \mathrm{~s}^{-1}$ and of $V_{f X}=165 \pm 30 \mathrm{~km} \mathrm{~s}^{-1}$, obtained from the Cowley D distribution injected in the vicinity of the $\mathrm{X}$ line. From equation (9) of paper 1 , this gives us an estimate of the field-parallel component of the tangential sheath flow velocity at the $\mathrm{X}$ line of $V_{s h X}=-55 \pm 65 \mathrm{~km} \mathrm{~s}^{-1}$. The field line acceleration effect will tend to make this value more negative if $V_{f X}$ is overestimated. Nevertheless, this is a highly significant result, as it either places the $\mathrm{X}$ line relatively close to the subsolar point, where the flow goes to zero, and/or aligns it with the magnetosheath flow streamline which is normal to the magnetosheath field. In addition, from equation (8) of paper 1 , we find that the Alfvén speed in the magnetosheath is $V_{A X}$ $=220 \pm 45 \mathrm{~km} \mathrm{~s}^{-1}$ in the vicinity of the $\mathrm{X}$ line (the field line accleration effect will tend to make this an underestimate).

From equation (13) of paper 1, we find that the product $\left(1+B_{s p}{ }^{\prime} / B_{s h}{ }^{\prime}\right)^{1 / 2} \cdot \cos \alpha$ is equal to 0.53 , where $\alpha$ is the angle that the normal to the $\mathrm{X}$ line (in the plane of the boundary) makes with the magnetosheath field at the $\mathrm{X}$ line and $B_{s p}{ }^{\prime}$ and $B_{s /}{ }^{\prime}$ are the components of the magnetosphere and magnetosheath fields, which are aligned with that normal. This places limits on the angle $\alpha: B_{s p}{ }^{\prime} B_{s l}{ }^{\prime}$ is required to be positive to give antiparallel field components across the $\mathrm{X}$ line, and a range of values between zero and infinity gives a range of $\alpha$ of $58^{\circ}-90^{\circ}$.

It is also valuable to compute some other variables at the $\mathrm{X}$ line, in order to check that the above estimates are sensible. Cowley [1982] assumed that 50\% of the incident magnetosheath ion population was transmitted through the rotational discontinuity (RD) (i.e., $t_{r}=N / N_{s h}=0.5$ ) and $50 \%$ was reflected back into the magnetosheath. This value is in rough accord with the valucs of the transmission cocfficient $t_{r}$ determined experimentally by Fuselier et al. [1991], although other studies have implied that this factor may be lower [Onsager et al., 1995; Lockwood et al., 1994]. Using a transmission factor $t_{r}$ of 0.5 , an anisotropy $A$ of 2 , and the fitted density for the transmitted Cowley $\mathrm{D}$ distribution, $N=$ $1.3 \mathrm{~A} \times 10^{7} \mathrm{~m}^{-3}$, we obtain a sheath density at the $\mathrm{X}$ line of $N_{s h X}=5 \times 10^{7} \mathrm{~m}^{-3}$. From $V_{A X}=220 \mathrm{~km} \mathrm{~s}^{-1}$ and equation (10) of paper 1 , the magnetosheath field at the $X$ line would then be $B_{s / h}=71 \mathrm{nT}$. Although all these values are highly plausible for a low-latitude reconnection site, they cannot be determined properly in this case because we do not know $t_{r}, A$ and $T / T_{s l}$.

Lockwood et al. [1994] employed simultaneous solar wind values to place limits on these unknown parameters. Unfortunately, for the data discussed in the present paper, the IMP 8 satellite was in an ideal location, but not tracked. Hence the analysis of Lockwood et al. [1994] cannot be repeated here. Nevertheless, their analysis should be possible with a large number of passes which do have simultaneous interplanetary magnetic field (IMF) or magnetosheath data and which display the feature in the cusp ion dispersion signature near the point A (Figure 2, paper 1), as in the pass studied here.

\section{Discussion and Conclusions}

We have analyzed in detail a cusp ion step which was observed by DMSP-F10 on the equatorward edge of a poleward moving event seen in the cusp region by the EISCAT radar. The combined observations are consistent with both being caused by pulsed reconnection, taking place at a location on the dayside magnetopause, as predicted by the pulsating cusp theory of Lockwood and Smith [1989]; Cowley et al. [1991], and Smith et al. [1992].

The pulsating cusp theory predicts cusp ion steps, but as mentioned in the introduction, steps can also be produced by spatial variations of the reconnection rate [Onsager et al., 1995; Weiss et al., 1995]. Lockwood [1995] and Lockwood and Smith [1994] have discussed how the plasma flow must be parallel to the step on both sides and hence a rotation of the flow across the step reveals that it is temporal and not spatial in origin. The flow vectors in Figure 1 reveal a small but persistent rotation toward northward with increasing latitude across the equatorward boundary of the second event, where the step discussed in this paper was observed. As discussed by Lockwood [1995], such a rotation eliminates a spatial cause of this particular step.

Second, the pulsating cusp model predicts that the cusp will be one of a series of poleward moving events [Lockwood et al., 1993a; Lockwood, 1994; 1995], as is found to be the case in these data. Not only does this prediction not fit with a spatial origin of the step, but it also supports the concepts of ionospheric flow excitation put forward by Cowley and Lockwood [1992] on which the prediction of cusp ions steps by Cowley et al. [1991] and Smith et al. [1992] was based. Note that no other model of the ionospheric effects of flux transfer events (here meaning magnetopause reconnection pulses) can explain cusp ion steps, as it is the only model in which each region of newly opened flux is appended directly equatorward of its predecessor. The concepts of flow excitation in these models are also supported by the relatively constant poleward flow observed by EISCAT during these events ( $V_{N}$ being roughly $500 \mathrm{~m} \mathrm{~s}^{-1}$ at all times). This is because induction effects mean that, on short response time scales, the reconnection pulses cause the open/closed boundary to migrate equatorward, rather than excite poleward flow in the Earth's frame [Lockwood et al., 1993b]. The poleward flow is inductively smoothed with a time constant which is estimated to be near $20 \mathrm{~min}$ and which is therefore considerably greater than the 4 min between the events discussed here [Lockwood, 1994]. The equatorward motions of the open/closed boundary can be seen in the behavior of the enhanced $T_{e}$ events, with each event forming equatorward of the one before, reflecting the equatorward crosion of the $\mathrm{OCB}$ during the reconnection pulse which gives rise to the event.

The uncertainties in determining the time-of-flight, lowenergy cutoff of the cusp/cleft ions mean that it is difficult to estimate the exact distance from the satellite to the reconnection site. However, we can state from inspection of the velocity distribution functions at any one time that an absolute minimum value is $6 R_{E}$ and the maximum value is $38 R_{E}$, which, broadly speaking, place the reconnection site somewhere on the dayside magnetopause. The first-order estimate of $16 R_{E}$ deduced by Lockwood et al. [1993a] falls near the center of this deduced range for $d_{o}$.

Using the time series of the distribution function at each energy level of the instrument has here provided us with a much more detailed view of the behavior of this cutoff as a function of time, and this gives the distance from the satellite to the $\mathrm{X}$ line to be $d_{o}=14.5 \pm 2 R_{E}$. This implies that the reconnection is at low latitudes on the dayside for these equi- 
nox conditions (for example, the subsolar point is at a distance of $14 R_{E}$ using the Tsyganenko T89 model for equinox and $K p$ of 6 [Lockwood and Smith, 1994]). A nearsubsolar location of the reconnection $\mathrm{X}$ line would be consistent with the deduced value of the field-aligned sheath flow speed near the $X$ line, which is only $V_{s h X}=-55 \pm 50 \mathrm{~km}$ $\mathrm{s}^{-1}$. This low value is very significant, when compared with the magnitude of the boundary-tangential sheath flow which will be several hundreds of kilometers per second at locations away from the nose of the magnetosphere. Therefore the $\mathrm{X}$ line either is close to the magnetopause stagnation point and/or is on a flow streamline which is orthogonal to the magnetosheath field (both giving a small along-field component of the sheath flow at the $\mathrm{X}$ line, $V_{s / 2}$ ). Thus if the $\mathrm{X}$ line is extensive, it must be aligned with that flow streamline. We have also shown that the $\mathrm{X}$ line makes a large angle $\alpha$ (in the range $58^{\circ}-90^{\circ}$ ) with the magnetosheath field.

In paper 1, it was estimated that the field lines must move of the order of $7.5 R_{E}$ along the magnetopause before their straightening becomes a significant factor, if the feature between $t_{A}$ and $t_{B}$ is to be detected. This finding is consistent with the estimated $d_{0}$ of $14.5 R_{E}$, because the $\cos \theta$ factor in equation (3) of paper 1 would become significant near the magnetic cusp.

The observations presented here yield a density of plasma at the $\mathrm{X}$ line of $1.3\left(A / t_{r}\right) \times 10^{7} \mathrm{~m}^{-3}$. Given that the anisotropy in the open LLBL, $A$, is typically of the order of 2 and the transmission factor $t_{r}$ appears to be about 0.5 or less, this density is of the order of $5 \times 10^{7} \mathrm{~m}^{-3}$. This value relates to inside any plasma depletion layer (PDL), and so is a minimum estimate of the sheath density outside the PDL. This is a high value, suggesting a reconnection site near the stagnation region with a high solar wind density. Similarly, the sheath temperature at the $\mathrm{X}$ line is $3.1 \times 10^{6} \times(1+2 A) / 3 h$, where the heating factor $h$ is the ratio of the (three-dimensional) ion temperature in the open LLBL to that in the sheath. Again, taking $A$ of 2, with a high $h$ of 2 also, yields a three dimensional sheath temperature at the $\mathrm{X}$ line of 2.6 $\times 10^{6} \mathrm{~K}$. This is typical of values in the sheath, but does not help define the position of the $X$ line, since the variations of sheath temperature with location are generally comparable with the fluctuations caused by changes in the temperature of the solar wind.

Magnetopause observations of the effects of reconnection strongly suggest a low-latitude dayside location of the $X$ line during southward IMF [Daly et al., 1984; Paschmann, 1984; Gosling et al., 1990; Rijnbeek et al., 1984]. This is consistent with analysis of cusp ion dispersion signatures at both mid altitudes [Phillips et al., 1993; Lockwood and Smith, 1994] and low altitudes [Reiff et al., 1977; Carlson and Torbert; 1980], although we must recognize that uncertainties are large for such studies. Note that previous determinations of the distance to the $\mathrm{X}$ line from low-altitude cusp observations have employed the observed convection velocity in the Earth's frame and hence assumed steady state conditions, such that the ionospheric projection of the X line (the OCB) is static. The method employed here is more general because it is based on time elapsed since reconnection and does not make any such assumption.

The finding that the field-aligned magnetosheath flow is near zero at the $\mathrm{X}$ line is interesting since that was also the case in the quasi-steady cusp pass studied, using the same techniques, by Lockwood et al. [1994]. Many more examples will be required to see whether this represents a general result.

Acknowledgements. Wc thank the director and staff of the EISCAT Scientific Association for their assistance. EISCAT is supported by the research councils of France, Germany, Sweden, Norway, and the United Kingdom. ML and CJD are supported by the UK Particle Physics and Astronomy Research Council (PPARC); MFS by NASA; TGO by NASA grant NAGW-505 and NSF grant ATM-9111754; and WFD at the Phillips Laboratory (program element 6101F, project 7601) and by AFOSR (program element $61102 \mathrm{~F}$, task 2311G5).

The editor wishes to thank P. T. Newell and another referee for their assistance in evaluating these papers.

\section{References}

Brace, L. H., R. F. Theis, and W. R. Hoegy, A global view of the $F$-region electron density and temperature at solar maximum, Geophys. Res. Lett., 9, 989-992, 1982.

Carlson, C. W., and R. B. Torbert, Solar wind injections in the morning auroral oval, J. Geophys. Res., 85, 2903-2908, 1980.

Cowley, S. W. H., The causes of convection in the Earth's magnetosphere: A review of developments during the IMS, Rev. Geophys., 20, 531-565, 1982.

Cowley, S. W. H. and M. Lockwood, Excitation and decay of solarwind driven flows in the magnetosphere-ionosphere system, Ann. Geophys., 10, 103-115, 1992.

Cowley, S. W. H., M. P. Freeman, M. Lockwood, and M. F. Smith, The ionospheric signature of flux transfer events, in CLUSTER Dayside Polar Cusp, Spec. Publ., ESA SP-330, edited by C. I. Barron, pp. 105-112, Eur. Space Agency Publ., Noordwijk, Netherlands, 1991.

Curtis, S. A., et al., DE-2 cusp observations: Role of plasma instabilitics in topside ionospheric heating and density fluctuations, Geophys. Res. Lett., 9, 997-1000, 1982.

Daly, P. W., M. A. Saunders, R. P. Rijnbeek, N. Sckopke, and C. $\mathrm{T}$. Russell, The distribution of reconnection geometry in flux transfer events using energetic ion, plasma, and magnetic data, J. Geophys. Res., 89, 3843-3854, 1984.

Escoubet, C. P., M. F. Smith, S. F. Fung, P. C. Anderson, R. A. Hoffman, E. M. Basinska, and J. M. Bosqued, Staircase ion signature in the polar cusp: A case study, Geophys. Res. Lett., 19, 1735-1738, 1992.

Fasel, G. J., Dayside poleward-moving auroral forms: A statistical study, J. Geophys. Res., in press, 1995.

Fuselier, S. A., D. M. Klumpar, and E. G. Shelley, Ion reflection and transmission during reconnection at the Earth's subsolar magnetopause, Geophys. Res. Lett., 18, 139-142, 1991.

Gosling, J. T., M. F. Thomsen, S. J. Bame, R. C. Elphic, and C. T. Russell, Plasma flow reversals at the dayside magnetopause and the origin of asymmetric polar cap convection, J. Geophys. Res., 95, 8073-8084. 1990.

Hill, T. W., and P. H. Reiff, Evidence of magnetospheric cusp proton acceleration by magnetic merging at the dayside magnetopause, J. Geophys. Res., 82, 3623-3628, 1977.

Lockwood, M., Ionospheric signatures of pulsed magnetopause reconnection in Physical Signatures of Magnetopause Boundary Layer Processes NATO ASI Ser. C, vol. 425, edited by J. Holtet and A. Egeland, pp. 229-243, Kluwar, Acad., Norwell, Mass., 1994.

Lockwood, M., Ground-based and satellite observations of the cusp: Evidence for pulsed magnetopause reconnection, in Physics of the Magnetopause, Geophys. Monogr. Ser., edited by B. U. O. Sonnerup, AGU, Washington, D. C., in press, 1995.

Lockwood, M., The location and characteristics of the reconnection $\mathrm{X}$ line deduced from low-altitude satellite and ground-based observations, 1, Theory, J. Geophys Res., this issue.

Lockwood, M., and C. J. Davis, The occurrence probability, width, and number of steps of cusp precipitation for fully pulsed reconnection at the dayside magnetopause, J. Geophys. Res., 100, 7627-7640, 1995a. 
Lockwood, M., and C. J. Davis, An analysis of the accuracy of magnetopause reconnection rate variations deduced from cusp ion dispersion characteristics, Ann. Geophys., in press, 1995b.

Lockwood, M., and M. F. Smith, Low altitude signatures of the cusp and flux transfer events, Geophys. Res. Lett., 16, 879-883, 1989.

Lockwood, M., and M. F. Smith, Reply to Newell, Geophys. Res. Lett., 17, 305-306, 1990.

Lockwood, M., and M. F. Smith, The variation of reconnection rate at the dayside magnetopause and cusp ion precipitation, J. Geophys. Res., 97, 14,841-14,847, 1992.

Lockwood, M., and M. F. Smith, Comment on "Mapping the dayside ionosphere to the magnetosphere according to particle precipitation characteristics" by Newell and Meng, Geophys. Res. Lett., 20, 1739-1740, 1993.

Lockwood, M., and M. F. Smith, Low and middle altitude cusp particle signatures for general magnetopause reconnection rate variations, 1, Theory, J. Geophys. Res., 99, 8531-8533, 1994.

Lockwood, M., and M. N. Wild, On the quasi-periodic nature of magnetopause flux transfer events, J. Geophys. Res., 98, 5935$5940,1993$.

Lockwood, M., W. F. Denig, A. D. Farmer, V. N. Davda, S. W. H. Cowley, and H. Luihr, Ionospheric signatures of pulsed magnetic reconnection at the Earth's magnetopause, Nature, 361(6411), 424, $1993 \mathrm{a}$.

Lockwood, M., J. Moen, S. W. H. Cowley, A. D. Farmer, U. P. Løvhaug, H. Lühr, and V. N. Davda, Variability of dayside convection and motions of the cusp/cleft aurora, Geophys. Res. Lett., 20, 1011-1014, 1993b.

Lockwood, M., T. G. Onsager, C. J. Davis, M. F. Smith, and W. F Denig, The characteristics of the magnetopause reconnection $\mathrm{X}$ line deduced from low-altitude satellite observations of cusp ions, Geophys. Res. Lett., 21, 2757-2760, 1994.

Newell, P. T., and C.-I. Meng, Ion acceleration at the equatorward cdge of the cusp: Low altitude observations of patchy merging, Geophys. Res. Lett, 18, 1829-1832, 1991.

Newell, P. T., and C.-I. Meng, Magnetopause dynamics as inferred from plasma observations on low-altitude satellites, in Physics of the Magnetopause, edited by B. U. O Sonnerup, Geophys. Monogr. Ser., AGU, Washington, D. C., in press, 1995.

Newell, P. T., W. J. Burke, C.-I. Meng, E. R. Sanchez, and M. E. Greenspan, Identification and observation of the plasma mantle at low altitude, J. Geophys. Res., 96, 35-45, 1991.

Nilsson, H., S. Kirkwood, L. Eliasson, O. Norberg, J. Clemmons, and $\mathrm{M}$. Boehm, The ionospheric signature of the cusp: A case study using Freja and the Sondrestrom radar, Geophys. Res. Lett., 21, 1923-1926, 1994.

Onsager, T. G., et al., Low-altitude observations and modeling of quasi-steady magnetopause reconnection, J. Geophys. Res., in press, 1995.

Paschmann, G., The Earth's magnetopause, in Achievements of the International Magnetospheric Study, IMS, Spec. Publ., ESA
SP-217, pp 53-64, Eur. Space Res. and Technol. Cent., Noordwijk, Netherlands, 1984.

Phillips, J. L., S. J. Bame, R. C. Elphic, J. T. Gosling, M. F. Thomsen, and T. G. Onsager, Well-resolved observations by ISEE 2 of ion dispersion in the magnetospheric cusp, J. Geophys. Res., 98, 13,429-13,440, 1993.

Reiff, P. H., T. W. Hill, and J. L. Burch, Solar wind plasma injection at the dayside magnetospheric cusp, J. Geophys. Res., 82, 479-491, 1977.

Rijnbeek, R. P., S. W. H. Cowley, D. J. Southwood, and C. T. Russell, A survey of dayside flux transfer events observed by the ISEE 1 and 2 magnetometers, J. Geophys. Res., 89, 786-800, 1984.

Smith, M. F., M. Lockwood, and S. W. H. Cowley, The statistical cusp: A simple flux transfer cvent model, Planet. Space Sci., 40, $1251,1992$.

Titheridge, J. E., Ionospheric heating beneath the magnetospheric cleft, J. Geophys. Res., 81, 1976.

Watermann, J., O. de la Beaujardiere, and P. T. Newell, Incoherent scatter radar observations of ionospheric signatures of cusp-like electron precipitation, J. Geomagn. Geoelectr., 44, 1195-1206, 1992

Watermann, J., D. Lummerzheim, O. del al Beaujardiere, P.T. Newell and F.J. Rich, Ionospheric footprint of magnetosheathlike particle precipitation observed by incoherent scatter radar, $J$. Geophys. Res., 99, 3855-3867, 1994.

Weiss, L. A., P. H. Reiff, H. C. Carlson, E. J. Weber and M. Lockwood, Flow-aligned jets in the magnetospheric cusp: Results from the Geospace Environment Modeling Pilot program., $J$. Geophys. Res. 100, 7649-7659, 1995.

Wickwar, V. B., and W. Kofman, Dayside auroras at very high latitudes: The importance of thermal excitation, Geophys. Res. Lett., II, 923-926, 1984.

Wickwar, V. B., L. L Cogger, and H. C. Carlson, The $6300 \AA$ $\mathrm{O}\left({ }^{1} D\right)$ airglow and dissociative recombination, Planet. Spcae Sci., 22.709-724, 1974

C.J. Davis and M. Lockwood, Rutherford Appleton Laboratory, Chilton, Didcot, OX11 0QX, United Kingdom. (e-mail: Internet. mike@eiscat.ag.rl.ac.uk)

W.F. Denig, Phillips Laboratory, PL/GPSG, Hanscom AFB, Bedford, MA 01731. (e-mail: Internet. wdenig @ nord.usafa.af.mil)

T.G. Onsager, Institute for the Study of the Earth, Oceans, and Space and Department of Physics, University of New Hampshire, Durham, NH 03824. (e-mail: Internet. onsager@unhggss1.unh.edu)

M. F. Smith, Laboratory for Extraterrestrial Physics, NASA Goddard Space Flight Center, Greenbelt, MD 20771. (e-mail: Internet. smith@lepmfs.gsf c.nasa.gov)

(Received November 28, 1994; revised April 25, 1995;

accepted April 25, 1995.) 